\title{
Vascular and Metabolic Factors in Alzheimer's Disease and Related Dementias: Introduction
}

\author{
Costantino Iadecola ${ }^{1}$
}

Received: 13 December 2015/Accepted: 15 December 2015/Published online: 22 February 2016

(C) Springer Science+Business Media New York 2016

Dementia, a progressive and irreversible cognitive deterioration typically associated with aging, has recently been recognized as one of the major health challenges of our century (Holtzman et al. 2011). There are $\approx 40$ million people suffering from dementia in the world, a number estimated to triplicate by 2050 due to the aging of the world population and the lack of effective treatments (Prince et al. 2013). The realization that the world will soon be faced with a dementia epidemic has led to national and international efforts to develop strategies to curb its devastating socioeconomic impact (Alzheimer's Association National Plan Milestone Workgroup et al. 2014; World Health Organization 2012).

The two major causes of dementia are Alzheimer's disease (AD), responsible for 70-80\% of cases, and dementia caused by vascular factors (Gorelick et al. 2011; Prince et al. 2013). AD is characterized neuropathologically by the presence of extracellular deposits of an amyloid substance (amyloid plaques) and intraneuronal aggregates of the microtubule-associated protein tau (neurofibrillary tangles) (Masters et al. 2015). The main component of amyloid plaques is amyloid- $\beta$ (A $\beta)$, a $40-42$ aminoacid peptide cleaved from the amyloid precursor protein (APP) by $\alpha$ - and $\beta$-secretase enzymes (Masters et al. 2015).

Cognitive impairment on vascular basis is caused by a wide variety of ischemic lesions. Multiple infarcts affecting several brain regions (multi-infarct dementia) or a single

Costantino Iadecola

coi2001@med.cornell.edu

1 Feil Family Brain and Mind Research Institute, Weill Cornell Medical College, 407 East 61st Street, New York, NY 10065, USA infarct in areas involved in cognition (strategic infarct dementia) are well established but rare causes (Iadecola 2013); rather, cognitive impairment on vascular basis results most commonly from discrete or confluent white matter lesions (white matter disease) caused by alterations of small arterioles of the basal ganglia and subcortical white matter (small vessel disease) (Gorelick et al. 2011). The term vascular cognitive impairment (VCI) refers to all the cognitive manifestation of cerebrovascular diseases, whereas "vascular dementia" indicates the most extreme case of VCI, in which multiple cognitive domains are affected interfering with day-to-day activities (Gorelick et al. 2011).

$\mathrm{AD}$ and VCI were traditionally considered distinct pathophysiological entities, AD being caused by neurodegeneration driven by $\mathrm{A} \beta$ and tau (Hardy 2006), and VCI caused by cerebral ischemia due to pathological changes in arterioles, i.e., arteriosclerosis, lipohyalinosis, and fibrinoid necrosis (small vessel disease) (Pantoni 2010). However, increasing evidence indicates that there is much overlap between these two conditions (Iadecola 2010). First, epidemiological studies have indicated that clinically diagnosed AD and VCI share common risk factors, such as hypertension, obesity, diabetes, etc., suggesting the involvement of common pathogenic factors (Casserly and Topol 2004). Second, community-based pathological studies have revealed that $\mathrm{AD}$ and cerebrovascular lesions coexist in 40-50\% of clinically diagnosed AD, making mixed AD-vascular dementia the most common cause of cognitive impairment in the aged (Schneider et al. 2007; Sonnen et al. 2007). Third, several studies have demonstrated that cerebral blood flow $(\mathrm{CBF})$ and its reactivity to vasoactive stimuli are reduced in patients with AD-type dementia, effects observed even in the presymptomatic stages of the diseases (Binnewijzend et al. 2015; Cantin 
et al. 2011; Iadecola 2013; Ruitenberg et al. 2005). Fourth, pathological studies have revealed an intriguing interaction between small basal ganglia ischemic lesions and $\mathrm{AD}$ pathology, such that their coexistence greatly amplifies the expression of the cognitive deficits beyond what would be expected based on the AD pathology alone (Esiri et al. 1999; Snowdon et al. 1997). These observations have suggested that vascular factors may play a role not only in VCI, but also in the development and evolution of $\mathrm{AD}$ (Iadecola 2004).

Experimental studies in mouse models overexpressing mutated forms of APP and exhibiting brain A $\beta$ accumulation have corroborated these clinical-pathological findings. $A \beta$ is a potent vasoconstrictor (Niwa et al. 2001; Thomas et al. 1996), reduces resting CBF (Niwa et al. 2002b) and attenuates the increase in CBF induced by endothelial cells (endothelium-dependent vasodilatation) and neuronal activation (functional hyperemia) (Iadecola et al. 1999; Niwa et al. 2000), key mechanisms regulating the cerebral circulation. Furthermore, A $\beta$ impairs cerebrovascular autoregulation, a fundamental response of the cerebral circulation that maintains $\mathrm{CBF}$ relatively independent of arterial pressure over a certain range (Niwa et al. 2002a). These alterations in neurovascular regulation reduce the cerebral blood supply and increase the susceptibility of the brain to cerebral ischemia (Zhang et al. 1997). Importantly, these vascular abnormalities are observed in the absence of deposition of $A \beta$ in amyloid plaques or around cerebral blood vessels (cerebral amyloid angiopathy), suggesting that soluble or oligomeric $A \beta$ is the vasotoxic species. The cerebrovascular effects of $A \beta$ are mediated in large part by activation of the free radicalproducing enzyme NADPH oxidase through the innate immunity receptor CD36, and are reversible by pharmacological or genetic approaches to scavenge radicals or block their production (Han et al. 2015; Iadecola et al. 1999; Nicolakakis et al. 2008; Park et al. 2013, 2008). However, these neurovascular alterations become irreversible in advanced disease, due to accumulation of $A \beta$ in cerebral blood vessels which leads to damage to endothelium, smooth muscle cells, and pericytes (Park et al. 2013, 2014). Collectively, the evidence to date suggests that $A \beta$, in addition to its well-established effects on synaptic function, also targets cerebral blood vessels leading to neurovascular dysfunction and lowering the threshold for cerebral ischemic injury. In support of this hypothesis, patients with $\mathrm{AD}$ are at greater risk for stroke (Chi et al. 2013; Tolppanen et al. 2013).

Additional evidence linking vascular factors to the pathogenesis of $\mathrm{AD}$ was provided by studies demonstrating that the cerebral vasculature is critical for the removal of $A \beta$ from the brain. $A \beta$ is produced normally during neural activity (Cirrito et al. 2005), but is promptly cleared from the extracellular space to prevent its accumulation. Indeed, failure of $A \beta$ clearance has emerged as a culprit in sporadic cases of AD (Mawuenyega et al. 2010). Brain A $\beta$ clearance is thought to rely on parenchymal and vascular mechanisms (Miners et al. 2014). In addition to parenchymal enzymes that degrade $A \beta$ (neprilysin, insulin degrading enzyme, plasmin, and endothelin converting enzyme) (Miners et al. 2008), A $\beta$ is removed (a) through perivascular pathways draining into the cervical lymph nodes (Tarasoff-Conway et al. 2015), and (b) by binding vascular transport receptors (LRP1, PICALM) and crossing the vascular wall to reach the circulation (Shibata et al. 2000; Storck et al. 2015; Zhao et al. 2015). A paravascular pathway involving astrocytic end-feet (glymphatic system), which has the potential to clear $A \beta$ from the brain (Iliff et al. 2012), has been recently discovered and could play a role. Cerebrovascular damage prevents $A \beta$ removal and leads to amyloid accumulation in brain and vessels (Faraco et al. 2015; Park et al. 2013). Therefore, the health of the cerebral vasculature is critical for $A \beta$ clearance, and vascular damage is likely to promote amyloid deposition also in $\mathrm{AD}$.

In this special issue of Cellular and Molecular Neurobiology, leading experts in the field address some of the key questions still outstanding concerning the role of vascular factors and $\mathrm{AD}$ pathology on cognitive health. The contributions span from the effects of $A \beta$ on cerebrovascular regulation and cognitive function to the mechanisms of $\mathrm{A} \beta$ clearance and their failure in $\mathrm{AD}$. The intriguing relationship between $\mathrm{AD}$ and regulation of body weight and metabolism is also examined. In addition, novel therapeutic approaches focusing on both parenchymal and vascular targets are examined. Data are presented on the reduction in $\mathrm{CBF}$ and on enlargement of perivascular space as diagnostic tools and potential biomarkers of early disease.

Other contributions focus on the cerebrovascular effects of risk factors linked to cognitive impairment, such as hypertension and diabetes, and on much needed animal models of VCI. The role of the blood-brain barrier is examined in the context of the cerebrovascular damage produced by hypertension, the major cause of VCI and a risk factor for $\mathrm{AD}$ as well. Based on the weight of the evidence, the rationale for advancing research priorities in vascular contributions to cognitive decline is also articulated.

Overall, these contributions provide a glimpse into the changing landscape of dementia research, which has shifted from an exclusive focus on neurodegeneration to a more balanced view implicating vascular factors, either independently or in concert with $\mathrm{AD}$ pathology, in the development and/or expression of cognitive decline (Snyder et al. 2014). The body of work presented in this issue 
supports the emerging notion that, in the absence of mechanistic treatments for dementia, maintenance of vascular and cognitive health is the best available option to contain the catastrophic societal and economic impact of the upcoming dementia epidemic (Iadecola 2013; Kuehn 2015).

\section{References}

Binnewijzend MAA, Benedictus MR, Kuijer JPA, van der Flier WM, Teunissen CE, Prins ND et al (2015) Cerebral perfusion in the predementia stages of Alzheimer's disease. Eur Radiol. doi:10. 1007/s00330-015-3834-9

Cantin S, Villien M, Moreaud O, Tropres I, Keignart S, Chipon E et al (2011) Impaired cerebral vasoreactivity to $\mathrm{CO}_{2}$ in Alzheimer's disease using BOLD fMRI. NeuroImage 58(2):579-587. doi:10. 1016/j.neuroimage.2011.06.070

Casserly I, Topol E (2004) Convergence of atherosclerosis and Alzheimer's disease: inflammation, cholesterol, and misfolded proteins. Lancet 363(9415):1139-1146. doi:10.1016/S01406736(04)15900-X

Chi N-F, Chien L-N, Ku H-L, Hu C-J, Chiou H-Y (2013) Alzheimer disease and risk of stroke: a population-based cohort study. Neurology 80(8):705-711. doi:10.1212/WNL. Ob013e31828250af

Cirrito JR, Yamada KA, Finn MB, Sloviter RS, Bales KR, May PC et al (2005) Synaptic activity regulates interstitial fluid amyloidbeta levels in vivo. Neuron 48(6):913-922. doi:10.1016/j.neuron. 2005.10.028

Esiri M, Nagy Z, Smith M, Barnetson L, Smith A (1999) Cerebrovascular disease and threshold for dementia in the early stages of Alzheimer's disease. Lancet 354(9182):919-920

Faraco G, Park L, Zhou P, Luo W, Paul SM, Anrather J, Iadecola C (2015) Hypertension enhances A $\beta$-induced neurovascular dysfunction, promotes $\beta$-secretase activity, and leads to amyloidogenic processing of APP. J Cereb Blood Flow Metab. doi:10. 1038/jcbfm.2015.79

Fargo KN, Aisen P, Albert M, Au R, Corrada MM, Alzheimer's Association National Plan Milestone Workgroup et al (2014) 2014 report on the milestones for the US National Plan to Address Alzheimer's Disease. Alzheimer's Dement 10(5 Suppl):S430-S452. doi:10.1016/j.jalz.2014.08.103

Gorelick PB, Scuteri A, Black SE, DeCarli C, Greenberg SM, Iadecola C et al (2011) Vascular contributions to cognitive impairment and dementia: a statement for healthcare professionals from the American heart association/american stroke association. Stroke 42(9):2672-2713. doi:10.1161/STR. 0b013e3182299496

Han BH, Zhou M-L, Johnson AW, Singh I, Liao F, Vellimana AK et al (2015) Contribution of reactive oxygen species to cerebral amyloid angiopathy, vasomotor dysfunction, and microhemorrhage in aged Tg2576 mice. Proc Natl Acad Sci USA 112(8):E881-E890. doi:10.1073/pnas.1414930112

Hardy J (2006) Alzheimer's disease: the amyloid cascade hypothesis: an update and reappraisal. J Alzheimer's Dis 9(3 Suppl):151-153

Holtzman DM, Morris JC, Goate AM (2011) Alzheimer's disease: the challenge of the second century. Sci Transl Med 3(77):77sr1. doi:10.1126/scitranslmed.3002369

Iadecola C (2004) Neurovascular regulation in the normal brain and in Alzheimer's disease. Nat Rev Neurosci 5(5):347-360. doi:10. $1038 / \mathrm{nrn} 1387$
Iadecola C (2010) The overlap between neurodegenerative and vascular factors in the pathogenesis of dementia. Acta Neuropathol 120(3):287-296. doi:10.1007/s00401-010-0718-6

Iadecola C (2013) The pathobiology of vascular dementia. Neuron 80(4):844-866. doi:10.1016/j.neuron.2013.10.008

Iadecola C, Zhang F, Niwa K, Eckman C, Turner SK, Fischer E et al (1999) SOD1 rescues cerebral endothelial dysfunction in mice overexpressing amyloid precursor protein. Nat Neurosci 2(2):157-161. doi:10.1038/5715

Iliff JJ, Wang M, Liao Y, Plogg BA, Peng W, Gundersen GA et al (2012) A paravascular pathway facilitates CSF flow through the brain parenchyma and the clearance of interstitial solutes, including amyloid $\beta$. Sci Transl Med 4(147):147ra111. doi:10. 1126/scitranslmed.3003748

Kuehn BM (2015) The brain fights back: new approaches to mitigating cognitive decline. JAMA. doi:10.1001/jama.2015. 15390

Masters CL, Bateman R, Blennow K, Rowe CC, Sperling RA, Cummings JL (2015) Alzheimer's disease. Nature Publishing Group, London, pp 1-18. doi:10.1038/nrdp.2015.56

Mawuenyega KG, Sigurdson W, Ovod V, Munsell L, Kasten T, Morris JC et al (2010) Decreased clearance of CNS beta-amyloid in Alzheimer's disease. Science 330(6012):1774. doi:10.1126/ science. 1197623

Miners JS, Baig S, Palmer J, Palmer LE, Kehoe PG, Love S (2008) Abeta-degrading enzymes in Alzheimer's disease. Brain Pathol 18(2):240-252. doi:10.1111/j.1750-3639.2008.00132.x

Miners JS, Palmer JC, Tayler H, Palmer LE, Ashby E, Kehoe PG, Love $S$ (2014) A $\beta$ degradation or cerebral perfusion? Divergent effects of multifunctional enzymes. Front Aging Neurosci 6:238. doi:10.3389/fnagi.2014.00238

Nicolakakis N, Aboulkassim T, Ongali B, Lecrux C, Fernandes P, Rosa-Neto P et al (2008) Complete rescue of cerebrovascular function in aged Alzheimer's disease transgenic mice by antioxidants and pioglitazone, a peroxisome proliferator-activated receptor gamma agonist. J Neurosci 28(37):9287-9296. doi:10.1523/JNEUROSCI.3348-08.2008

Niwa K, Younkin L, Ebeling C, Turner SK, Westaway D, Younkin S et al (2000) Abeta 1-40-related reduction in functional hyperemia in mouse neocortex during somatosensory activation. Proc Natl Acad Sci USA 97(17):9735-9740

Niwa K, Porter VA, Kazama K, Cornfield D, Carlson GA, Iadecola C (2001) A beta-peptides enhance vasoconstriction in cerebral circulation. Am J Physiol Heart Circ Physiol 281(6):H2417$\mathrm{H} 2424$

Niwa K, Kazama K, Younkin L, Younkin SG, Carlson GA, Iadecola C (2002a) Cerebrovascular autoregulation is profoundly impaired in mice overexpressing amyloid precursor protein. Am J Physiol Heart Circ Physiol 283(1):H315-H323. doi:10. 1152/ajpheart.00022.2002

Niwa K, Kazama K, Younkin SG, Carlson GA, Iadecola C (2002b) Alterations in cerebral blood flow and glucose utilization in mice overexpressing the amyloid precursor protein. Neurobiol Dis 9(1):61-68. doi:10.1006/nbdi.2001.0460

Pantoni L (2010) Cerebral small vessel disease: from pathogenesis and clinical characteristics to therapeutic challenges. Lancet Neurol 9(7):689-701. doi:10.1016/S1474-4422(10)70104-6

Park L, Zhou P, Pitstick R, Capone C, Anrather J, Norris EH et al (2008) Nox2-derived radicals contribute to neurovascular and behavioral dysfunction in mice overexpressing the amyloid precursor protein. Proc Natl Acad Sci USA 105(4):1347-1352. doi:10.1073/pnas.0711568105

Park L, Zhou J, Zhou P, Pistick R, Jamal S El, Younkin L et al (2013) Innate immunity receptor CD36 promotes cerebral amyloid angiopathy. Proc Natl Acad Sci USA 110(8):3089-3094. doi:10. 1073/pnas. 1300021110 
Park L, Koizumi K, Jamal S El, Zhou P, Previti ML, Van Nostrand WE et al (2014) Age-dependent neurovascular dysfunction and damage in a mouse model of cerebral amyloid angiopathy. Stroke 45(6):1815-1821. doi:10.1161/STROKEAHA.114. 005179

Prince M, Bryce R, Albanese E, Wimo A, Ribeiro W, Ferri CP (2013) The global prevalence of dementia: a systematic review and metaanalysis. Alzheimer's Dement 9(1):63.e2-75.e2. doi:10. 1016/j.jalz.2012.11.007

Ruitenberg A, den Heijer T, Bakker SLM, van Swieten JC, Koudstaal PJ, Hofman A, Breteler MMB (2005) Cerebral hypoperfusion and clinical onset of dementia: the Rotterdam Study. Ann Neurol 57(6):789-794. doi:10.1002/ana.20493

Schneider JA, Arvanitakis Z, Bang W, Bennett DA (2007) Mixed brain pathologies account for most dementia cases in community-dwelling older persons. Neurology 69(24):2197-2204. doi:10.1212/01.wnl.0000271090.28148.24

Shibata M, Yamada S, Kumar SR, Calero M, Bading J, Frangione B et al (2000) Clearance of Alzheimer's amyloid-ss(1-40) peptide from brain by LDL receptor-related protein-1 at the blood-brain barrier. J Clin Investig 106(12):1489-1499. doi:10.1172/ JCI10498

Snowdon D, Greiner L, Mortimer J, Riley K, Greiner P, Markesbery W (1997) Brain infarction and the clinical expression of Alzheimer disease. The nun study. JAMA 277(10):813-817

Snyder HM, Corriveau RA, Craft S, Faber JE, Greenberg SM, Knopman D et al (2014) Vascular contributions to cognitive impairment and dementia including Alzheimer's disease. Alzheimer's Dement . doi:10.1016/j.jalz.2014.10.008
Sonnen JA, Larson EB, Crane PK, Haneuse S, Li G, Schellenberg GD et al (2007) Pathological correlates of dementia in a longitudinal, population-based sample of aging. Ann Neurol 62(4):406-413. doi:10.1002/ana.21208

Storck SE, Meister S, Nahrath J, Meißner JN, Schubert N, Di Spiezio A et al (2015) Endothelial LRP1 transports amyloid- $\beta 1-42$ across the blood-brain barrier. J Clin Investig 126(1):1-14. doi:10.1172/JCI81108

Tarasoff-Conway JM, Carare RO, Osorio RS, Glodzik L, Butler T, Fieremans E et al (2015) Clearance systems in the brainimplications for Alzheimer disease. Nat Rev Neurol 11(8):457-470. doi:10.1038/nrneurol.2015.119

Thomas T, Thomas G, McLendon C, Sutton T, Mullan M (1996) BAmyloid-mediated vasoactivity and vascular endothelial damage. Nature 380:168-171

Tolppanen A-M, Lavikainen P, Solomon A, Kivipelto M, Soininen H, Hartikainen S (2013) Incidence of stroke in people with Alzheimer disease: a national register-based approach. Neurology 80(4):353-358. doi:10.1212/WNL.0b013e31827f08c5

World Health Organization (2012) Dementia a public health priority. World Health Organization, Geneva

Zhang F, Eckman C, Younkin S, Hsiao KK, Iadecola C (1997) Increased susceptibility to ischemic brain damage in transgenic mice overexpressing the amyloid precursor protein. J Neurosci 17(20):7655-7661

Zhao Z, Sagare AP, Ma Q, Halliday MR, Kong P, Kisler K et al (2015) Central role for PICALM in amyloid- $\beta$ blood-brain barrier transcytosis and clearance. Nat Neurosci 18(7):978-987. doi: $10.1038 / \mathrm{nn} .4025$ 